(ii) The traditional calculation of average speed to two places of decimals is misleading unless the relevant corrections have been included. The second decimal place was doubtless originally introduced to avoid a rounding error which has an amplitude equivalent in distance to $2 \frac{1}{2}$ miles, in a 24-hour run. Present knowledge of random position errors make such accuracy unjustified over a single 24 -hour period and it can be seen that systematic errors are unlikely to justify the second place when such runs are summed.

(iii) The statistical analysis of service speed is liable to be erroneous without knowledge of how the speeds have been calculated.

(iv) The theoretical advantages of mercator sailing over mean latitude sailing are shown to be severely qualified when used for average speed calculations without the necessary correction. For distances of up to 600 miles, uncorrected mercator methods result in greater systematic errors except when the latitude is greater than about $45^{\circ}$ and the course is between about $45^{\circ}$ and $85^{\circ}$ from the meridian.

\title{
REFERENCES
}

1 Williams, J. E. D. (1950). Loxodromic distances on the terrestrial spheroid. This Journal, 3, 133 .

2 Sadler, D. H. (1956). Spheroidal sailing and middle latitude. This Journal, 9, 37 I.

3 Turner, R. J. (1970). Rhumb-line sailing with a computer. This Journal, 23, 233.

4 Burton, S. M. (1951). Nautical Tables, Tables 3 and 3 a, 4 th Edition. G. Philip \& Son.

5 Moody, A. B. $\left(195^{2}\right)$. Early units of measurements and the nautical mile. This Journal, 5,262

6 Ritchie, G. S. (1970). Comment on 'Metrication and the nautical mile'. This Journal, 23, 388 .

7 Llewellyn, M. R. H. (1970). Rhumb-line and great-circle sailings. This Journal, 23, 119.

8 Moss, B. J. (1969). Exploration with a computer on rhumb-line sailing. This Journal, 22, $24^{2}$.

\section{High-Speed Vessels and the Collision Regulations}

\author{
Captain G. H. Draysey \\ (Hydrofoil Commander)
}

IT has become increasingly apparent that there is a pressing need to amend the Collision Regulations with special regard for the requirements of high-speed vessels. My experience as a Commander of a hydrofoil on a scheduled passenger service, in an area of high traffic density, has led me to write this paper and to add weight to the argument in favour of an early alteration of the existing Rules.

There are more and more types of vessel today capable of speeds in excess of 40 and indeed up to 60 or more knots. In the Solent area alone, there are two hovercraft services and a hydrofoil service. In addition there are the experimental 
craft of the National Physical Laboratory, the Inter-Service Hovercraft Unit and several manufacturers use the area as a testing ground for their vessels. There are all types of high-speed vehicles proceeding in all directions, at speeds which 10 years ago would have been considered impossible.

The main points to be considered are the problems of identification at night, the imminence of collision due to high closing speeds and a change in the ability to manœuvre.

Identification. The problem of identification of vessels moving at high speed is the most important. The majority of seafarers are conditioned to speeds in the region of 15 knots and their reactions are geared accordingly. An alteration of course, a change in speed is carefully thought out with minutes in hand. Unfortunately, one may not have so much time in hand if the other vessel is approaching at $4 \circ \mathrm{knots}$ and you are the 'giving-way' vessel, and have not recognized the danger.

At present the only provision that has been made is to equip cushion craft with a flashing orange light. This light was originally intended to indicate that the craft may have been affected by cross winds, so that the navigation lights were not necessarily showing the direction of movement. It did not indicate a high speed.

This flashing orange light is now fitted to all types of cushion craft and so its original purpose has been lost. The V.T.r and H.M.2 types of craft are of a rigid side design, with a water-screw propulsion, thus not being so greatly affected by the wind.

A hydrofoil is classed as a conventional vessel and carries the normal navigation lights in the normal positions and so has no identification signal. I have heard the skippers of local ferries and pleasure boats, and several pilots, pass the comment that it is difficult to identify a hydrofoil and take the appropriate action in good time.

If all high-speed vessels were equipped with the flashing orange light, they would be able to spot one another quickly and be readily identified by slower vessels. The only detail thus remaining is the problem of leeway affecting the aspect of the navigation lights on a conventional hovercraft. This might be overcome by the amendment of the rules which I will describe later.

Imminence of Collision. Regarding my second point of the imminence of collision due to high speeds, one may consider two hovercraft crossing at their normal cruising speed. At I mile from collision point the commander has just 80 seconds to act, although the craft may be nearly 2 miles apart. A similar situation can occur at night, with a slower vessel crossing the course of a highspeed craft, broad on the bow. The Master may not recognize the situation and decide to stand on, as he considers that he has time to cross. If he watches the bearing, he will appreciate the danger of collision and may have as much as a minute to take the appropriate action! As J. García-Frías has said, 'single responsibility is proving inadequate'.1

Some have advocated that high-speed craft should be required to give way at all times ${ }^{2}$ this was said of the hovercraft originally-but this is not always practicable. A hydrofoil, for instance, must keep sufficient water under her in case it is necessary to become hull-borne, and if two high-speed craft are involved in a situation, who gives way?

It would seem that the answer to this problem would be the abolition of the 'stand-on vessel' as required in Rule $2 \mathrm{r}$. If both vessels were required to alter 
course in a manner laid down by legislation whenever a collision seemed possible, the differing speeds would be relatively unimportant.

The regulation could read: 'Wherever danger of collision exists between two vessels underway, each vessel shall alter course to starboard, so that the bearing of the other moves in an anti-clockwise direction, excepting the case of vessels overtaking. Such alteration to be in good time and to be large enough to be recognized by the other vessel.'

The annex to Captain Thompson's suggested Revised Rules covers the alterations required for the different angles on the bow. ${ }^{3}$

This basic rule would apply in poor visibility, darkness or in clear weather. Both mariners knowing that the other will alter to starboard and so there cannot be that nagging doubt in anyone's mind- 'is he going to alter in time or should I move instead of standing on ?'

If the responsibility was on both vessels equally to give way, the aspect of the lights would not be quite so important in the case of a hovercraft. The flashing light would warn the mariner of the approach of a high-speed vessel, thus a more careful watch on its bearing would be kept, even before the navigation lights could be recognized. A change in aspect would indicate that an alteration of course had been made.

Mancuvrability. A point to be noted is that most high-speed craft, whether cushion or foil borne, are somewhat restricted in their mancuvrability by the very nature of their design. Neither craft is capable of a tight turn at speed, but they have the saving grace of being able to stop in a very short distance, even at high speeds. This enables these craft to navigate in restricted visibility with the knowledge that they can stop in less than half the visible distance.

A hovercraft tends to sideslip at speed when making a turn and in a following wind can become rather difficult to control; thus an early alteration of course is essential when avoiding a collision.

A hydrofoil has a large turning circle, owing to the relatively small surface area of the rudder being in the water, but will react quickly to large alterations of the helm, even in craft not fitted with trim-tabs on the foils.

Another factor is the high 'minimum' speed of these vessels. I understand that a hovercraft loses steerage way at about 12 knots, although the SRN. 4 is able to manœuvre at low speeds, by turning the engine mountings on the vertical axis. A hydrofoil comes off the foils at about 16 knots, thus the clause requiring a vessel to proceed at a moderate speed in fog must also be reconsidered. What is a moderate speed in this age of modern technology? It may be argued that it is a speed allowing a vessel to stop in half the visible distance. ${ }^{4}$

Local by-laws occasionally recognize the need for legislation to minimize the dangers by providing separate buoyed channels for hovercraft use and requiring special radio watches to be kept. The commercial use of high-speed craft is expanding rapidly. Hydrofoils are used extensively in the Baltic, in the Mediterranean and as far afield as Australia. There are two services operating in the United Kingdom and a third suggested for the Thames area. Hovercraft cross the Channel at 60 knots and have been used for numerous tasks around the world.

It is possible in the future, there may be large, high-speed craft capable of transatlantic voyages. The need to recognize the possible dangers is urgent, and an early amendment to Collision Regulations is required. 


\title{
REFERENCES
}

1 García Frías, J. (1970). The revision of the Rules. This Journal, 23, 71.

2 Clissold, P. C. H. (1969). Why the Rules need changing. This Journal, 22, 286.

3 Thompson, P. A. (1970). Revised Rules for preventing collisions at sea. This Journal, 23, 81 .

4 Dickson, A. F. (1969). Changing the Collision Regulations. This Journal, 22, 447.

\section{A Note on the Use of DCF for Marine Project Evaluation}

\author{
J. S. McKenzie \\ (Marine \& General Computer Consultancy (I.O.M.) Ltd.)
}

King's observation ${ }^{1}$ that a false impression could be gained from long-term savings that do not take account of the time value of money is no doubt true if all aspects and factors of comparative projects are taken into account. However, he must think readers a little naive if he offers his Fig. 3 as a full interpretation of the possible savings from installing the various levels of shipborne automation explored in my recent article. ${ }^{2}$ An examination of Section 8 (Cost Equations) will show that the DCF technique was deliberately discarded in order to simplify the argument. In fact, there was an additional note-deleted by the Editor through lack of space-which observed that the appraisal could be based on the assumption that the discount rate was equal to the escalation rate of the savings occasioned by taking into account the rise in wages, victualling, \&c. over the equivalent project period.

Omission or no, DCF techniques should not be treated as superficially as King appears to do in his note. The improvement in NPV at various discount rates is quite meaningless unless related to the projected variation in the cash flows. The essence of DCF is the ability to consider such flows in detail and work on elements or vectors in the cost matrices; continually refining the estimates of fixed outgoings in year $i$ or the rate of advance of, say, wages in years $m$ to $n$. Looking again at Table III in 'Manning Reductions and the Cost of Navigation' we see that wages, both at the base level and for subsequent stages, would need to be assessed at one level of escalation, and the victualling and incidentals at others. Furthermore, each of the incidentals would need close examination to determine whether their escalation rates were compatible and could be generalized. Then attention would need to be directed to the maintenance of accommodation and equipment, as these certainly could not be considered equal. They would reflect different rates of wage increases and would need to take into account advances in technology over the period of the project.

It would seem that only when we look at direct capital investment, or the lack of it, could we afford to neglect a detailed study, but even here it was noted that the equipment costs for stage 4 were 'of an order' rather than specific. Where does that leave us when we turn to the question of whether DCF should be used ? Certainly when we have determined the appropriate rates of escalation and the correct time for payment or receipt of monies we are approaching a better 